\title{
DESIGN AND DEVELOPMENT OF ERGONOMIC TABLE AND ANALYZE USING RULA ANALYSIS
}

\author{
Mohd Hidayat Ab Rahman*1, Nurul Ain Maidin ${ }^{1}$, Umi Hayati Ahmad ${ }^{1}$, Mohd Salahuddin Mohd Basri², \\ Mohd Nazri Ahmad ${ }^{1}$, Ridhwan Jumaidin ${ }^{1}$, Mohd Hairizal Osman ${ }^{1}$ and Mohammad Khalid Wahid ${ }^{1}$ \\ 'Department of Manufacturing Technology, Faculty Mechanical and Manufacturing Engineering Technology, Universiti \\ Teknikal Malaysia Melaka, Malaysia. \\ ${ }^{2}$ Department of Process and Food Engineering, Faculty of Engineering, Universiti Putra Malaysia, 43400 Serdang, \\ Selangor, Malaysia.
}

* Corresponding author: Mohd Hidayat Ab Rahman

Email: mohdhidayat@utem.edu.my

\begin{abstract}
Ergonomics and design have made the greatest relation in producing an artifact or creating a workplace. A computer table is widely used in classrooms in universities. However, the problems of the current computer table have been detected through the results of RULA analysis. In this project, a survey of the questionnaire was done and the anthropometric data have also been collected. The dimensions of the current computer table are then collected and the deficiencies of the current computer table have been focused on RULA analysis. A new structural design of the computer table has been designed, in order to meet the requirements of ergonomics. A product of the new design of ergonomics computer table is made and has been focused on RULA analysis to define the improvement between both tables. The paper showed a comparison between the current computer table and the new ergonomics computer table were analyzed. The improvement of the new ergonomics computer table was identified and reduced the injuries and disorders. A further investigation on better working posture when using a computer table is required, while further improvement for the product design of a new ergonomics computer table is needed, as well as the application of the ergonomics design aspect in our life.
\end{abstract}

Keywords: Musculoskeletal Disorder; Design and Development; RULA;

\section{INTRODUCTION}

Nowadays, computer usage plays an important role in our life, where numerous tasks can be carried out through its usage. Even the technology has been improved, the pc, particularly a desktop computer, which is also known as a personal computer that is only dedicated for normal use at just one place on a desk or table due to its size and power supply requirements. The most common configuration of a desktop computer has a central processing unit, motherboard, disk storage, a keyboard, and a mouse for input, whereas a computer monitor, speakers, and infrequently print outputs. The comfortable position during these activities is important, especially coupled with long hours of work to potentially avoid ergonomics risk factors or injuries.

However, to pursue improvements in this technology, individuals usually disregard the conformity of the table, as long they can utilize the table to carry out their respective responsibilities. The uncomfortable of body posture that perpetually works in front of a computer and is desk-bound will result in the occurrence of Work-related Musculoskeletal Disorders (WMSDs) at the neck and upper limbs, such as carpal tunnel syndrome, tendonitis, thoracic outlet syndrome, and tension neck syndrome. From ergonomics knowledge, the ergonomics risk factors while using the new product or doing computer work can reduce its possibilities from injury. The analysis of the computer table will be taken by using anthropometric data, and the process of the new design of ergonomics computer table will then be proceed based on the result analysis in this research. This research is focused on the new design and development of ergonomics computer table based on anthropometry data of students. Those students that selected are frequent users, mainly students who usually use the computer Studio's computer table.

Ergonomics emphasize the human fit environment, minimize fatigue, and discomfort through product design and development. Ergonomics mostly applies in office furniture as the design needs to take interactions between the products and users into accountability ${ }^{1}$. With the definitions, we can summaries that Ergonomics is focused on the fulfillment of the workplace to make sure the environment is designed to be wellorganized, safe conducive. Effective work system design with ergonomics can implement a wellbalanced between end-task users and demands. This can enhance the performance of the workers, facilittae in carrying their tasks and responsibilities, introduce proper safety as well as well-being, in terms of mentality and physically. Abandonment of ergonomic principles applications causes discomfort, pain, and 
inefficiency to users. The aim for the design of workplaces is to design for as many people as possible and to know the Ergonomic principles of posture and movement that is fundamental for the provision of a safe, healthy, and comfortable work environment.

\section{ERGONOMICS PRINCIPLE}

A few basic principles have developed from the ergonomics field for the past decades. These principles should be followed accordingly to ensure that the designed work is meant to be fit with the workers. The fundamental principles include aesthetics, ease to use, safety, comfort, productivity, and performance ${ }^{2}$. Aesthetics in terms of beauty are commonly related to appearance, colours, and shape. Ergonomics added this part for the market needs to offer jobs that fit the workers. Aesthetics values are typically related to tools used that associated with the job.

Therefore, a workplace which is decorated dedicatedly reduces the workers' stress level as they can fully emerge into the working condition physically and mentally. Ease to use is related between the working and tools equipment. Workers should be responsible for keeping all the tools within the range that able to reach within hand length. However, the aspect of ease of use must put into consideration for all tools to ensure they are accessible easily by any individual who requires it.

Safety is the key factor, especially while performing a task. Safety consists of the working environment and tools used. It is vital to design spacious work areas for workers to ensure the jobs are accessible and done quickly. The working tools with safety measurements must be handled carefully. A comfortable atmosphere encourages workers to work better when performing a task. Moreover, a comfortable zone helps the workers to be stress-free, which can prevent ergonomics risk factors among them. With ergonomics, not only comfort and health can be affected both directly and indirectly, but also the quality and efficiently of the work being done ${ }^{3}$. Productivity is well associated with performance, as the performance is directly proportional to productivity. Workers' performance lies within the working aspects include the ergonomics itself.

Ergonomics are meant to enable workers to fit the job given based on their basic needs in order to ensure productivity and performance. From all the principles that have stated above, we can conclude that well performance job can be achieved by applying ergonomics principles into tasks. Some of the studies have shown that ergonomics principles are known to be effective in solving problems related to work injuries.

\section{ANTHROPOMETRY}

Anthropometry is the study of the physical and dimensional measurement of humans. A distinction has been made between applied anthropometry, sometimes referred as to engineering anthropometry, and the more academic anthropometry that is used in research in conjunction with other areas of human biology ${ }^{3}$.

In addition, a further distinction is made within applied anthropometry, based on the techniques used to gather the raw data. They can also provide measures of surface area or volume, which are generally difficult to obtain with traditional instruments. Anthropometric design principle typically used for equipment or facilities that can be adjusted to fit a wider range of individuals $s^{4-5}$. The true design should have used the body dimensions for a combined male and female population. Anthropometry provides a scientific basis for analyzing and designing elements of the workplace so that they fit people of different sizes.

Furthermore, the field of applied anthropometry relates basic measures of human size, strength, and bodily motion to very helpful design criteria used by designers interested in innovative and creative things that fit or otherwise better match the size or other aspect of the human body. The following ergonomics guidelines for sitting work ${ }^{6}$ : (1) The person must be ready to reach the whole work area without stretching or twisting necessary.

(2) The work table and chair ought to be designed in order that the work surface is relatively at the equivalent level as the elbows. Moreover, students 'anthropometric measurements also additionally varied wide across completely different age groups, at intervals an equivalent age groups, and between genders and completely different cultures ${ }^{7-11}$.

\section{MUSCULOSKELETAL DISORDER (MSD)}

Both workspaces and designed tools have an important effect on body posture, mainly wrists, shoulders elbows and other body parts, which is related to pathological musculoskeletal changes. MSD happens due to repetitive works and heavy lifting, which may lead to fatigue and failure of body tissues. An unhealthy lifestyle that involves repetitive work and movement is the leading cause of $M S D^{12}$. Our body parts will become fatigued if we are exposed to repetitive and tedious work daily. For example, a person might feel cramp, sore or pain in the neck, shoulder and waist area when doing computer work for an extended period. MSD cases have reported being raised each year, which means workers are more likely to expose to MSD, and it will lower works' efficiency and productivity. Table 1 below shows the Outlines Occupational Risk Factors and Symptoms. 
Malaysian Journal of Public Health Medicine 2020, Special Volume 1: 138-144

TABLE 1. Outlines occupational risk factors and symptoms

\begin{tabular}{|c|c|c|}
\hline Disorder & Occupational risk factors & Symptoms \\
\hline Tendonities/tenosynovitis & $\begin{array}{l}\text { Repetitive wrist motions } \\
\text { Repetitive shoulder motions } \\
\text { Sustained hyperextension of arms } \\
\text { Prolonged load on shoulders }\end{array}$ & $\begin{array}{l}\text { Pain, weakness, swelling, } \\
\text { burning sensation or dull } \\
\text { ache over the affected } \\
\text { area }\end{array}$ \\
\hline $\begin{array}{l}\text { Epicondylitis (elbow } \\
\text { tendonitis) }\end{array}$ & $\begin{array}{l}\text { Repeated or forceful rotation of the } \\
\text { forearm and bending of the wrist at the } \\
\text { same time }\end{array}$ & $\begin{array}{l}\text { Same symptoms as } \\
\text { tendonitis }\end{array}$ \\
\hline Carpal tunnel syndrome & Repetitive wrist motions & $\begin{array}{l}\text { Pain, numbness, tingling, } \\
\text { burning sensations, } \\
\text { wasting of muscles at the } \\
\text { base of the thumb, dry } \\
\text { palm }\end{array}$ \\
\hline DeQuervain's disease & $\begin{array}{l}\text { Repetitive hand twisting and forceful } \\
\text { gripping }\end{array}$ & $\begin{array}{l}\text { Pain, numbness, swelling } \\
\text { of the hands }\end{array}$ \\
\hline Thiracic outlet syndrome & $\begin{array}{l}\text { Prolonged shoulder flexion } \\
\text { Extending arms above shoulder height } \\
\text { Carrying loads on the shoulder }\end{array}$ & $\begin{array}{l}\text { Pain, numbness swelling of } \\
\text { the hands }\end{array}$ \\
\hline Tension neck syndrome & Prolonged restricted posture & Pain \\
\hline
\end{tabular}

\section{RAPID UPPER LIMB ASSESSMENT (RULA)}

Rapid Upper Limb Assessment (RULA) is a general analysis which designed for the work designed, to evaluate the exposure of individual workers to ergonomic risk factors associated with upper extremity MSD, RULA Assessment Tool was developed. The RULA ergonomic assessment tool considers biomechanical and postural load requirements of job tasks/demands on the neck, trunk and upper extremities. In RULA worksheet, the evaluator will assign a score for each of the following body regions: upper arm, lower arm, wrist, neck, trunk, and legs. RULA was designed for easy use without the need for an advanced degree in ergonomics or expensive equipment ${ }^{13-15}$.

\section{METHODOLOGY}

Figure 1 shows the research methodology for this research from the beginning until the research accomplishment. The flow chart simplifies the steps that will be taken the first step and continue with what will be performed for the next step until the final step to completing achieving this research.

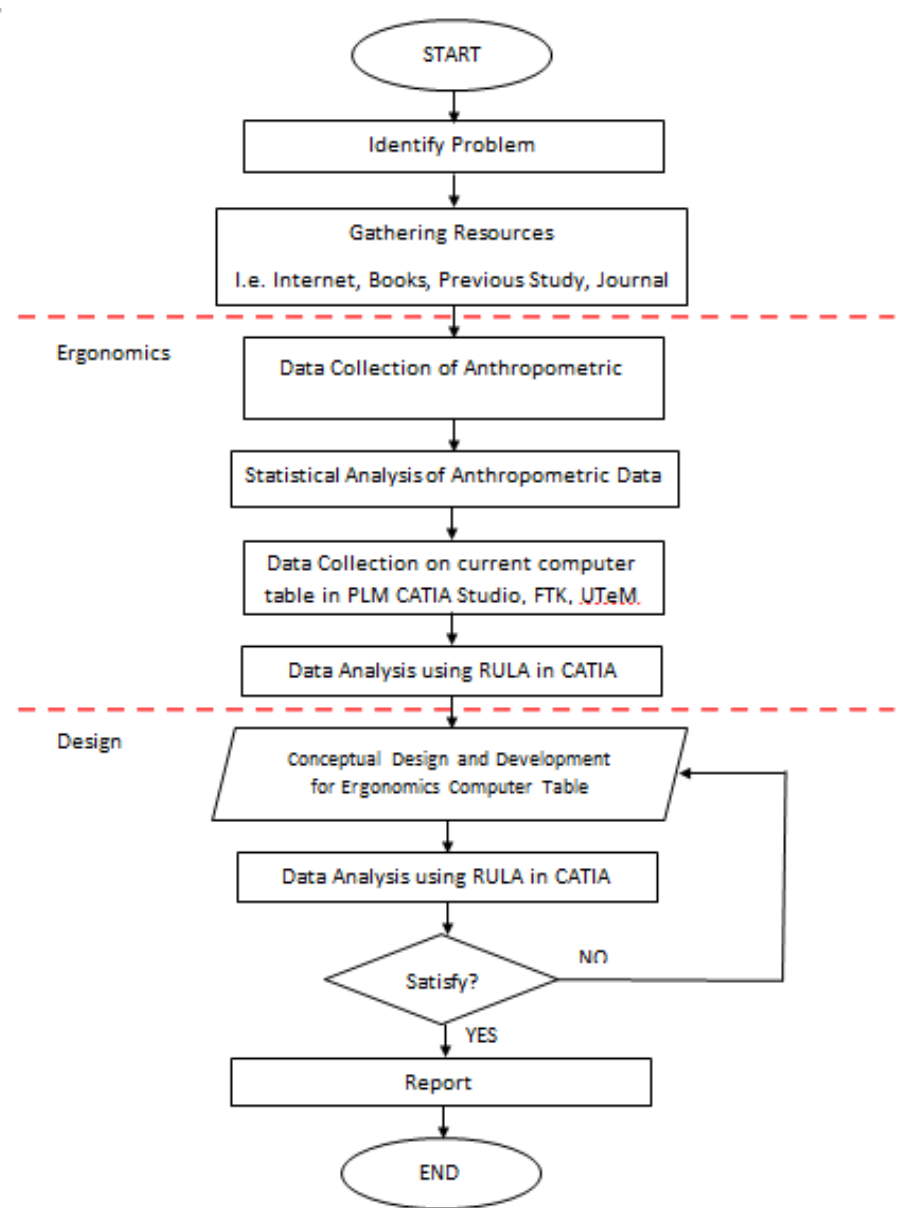

Fig. 1: Research Methodology 


\section{PROCEDURES}

Firstly, taking the measurements of the current computer table in the computer Studio. After that, for the measuring processes, collect the anthropometric data from those students that selected are the frequent users, mainly students who usually use the computer Studio's computer table. After those data are collected, both of the data will apply to CATIA software for analyzing process. For the measurement of the current computer table in computer Studio, the dimensions usually will be taken such as height, width, depth, and other parts of the dimensions that included in this current computer table design. The drawing needs to use along with the anthropometric data in analyzing process for defining the ergonomics concept of the computer table. There will be 100 students take as samples both males and females, for measuring the body dimensions. The dimensions are presents in a normal distribution, and finally, the statistical analysis has been done to get the population of students. When the current computer table's dimensions and the anthropometric data are completely collected, the analyzing process will be using CATIA software. Lastly, the final process for this project is to design and develop a new ergonomics computer table. The idea of a new computer table is very important for every user's in finding comfortably of the workplace while doing the computer job for a long period without having any ergonomics risk factor or injuries.
The new design of the computer table and then will proceed with the steps the same as the current computer table to ensure that it follows the ergonomics prospect.

\section{RESULTS}

The anthropometric data of students have been taken and analyzed to get their percentile. The percentile will be used in design analysis to define ergonomics aspect for the current computer table in computer Studio. The anthropometric data were taken for 24 parts for human body dimension. The percentile taken was 5th percentile, 50th percentile, and 95th percentile. From the normal distribution, mean and standard deviation can be defined which is get from percentile of body dimension for students.

From the anthropometric database collected, it will be used as guidance in designing a new concept of the ergonomics computer table. 50th percentile is the average of the database, will be used as an appropriate percentile.50th percentile is chosen as the main database for this project is because of there is different anthropometry of students who used the computer table which all of them will use the same computer table to do their work. Table 2 below shows the concept evaluation by using the Pugh method.

TABLE 2. Concept evaluation by using Pugh method

\begin{tabular}{|c|c|c|c|c|}
\hline Criteria & & & & \multirow{13}{*}{$\begin{array}{l}\text { I } \\
\text { I } \\
\text { క }\end{array}$} \\
\hline Table top can be adjusted & 1 & 2 & 3 & \\
\hline Keyboard level can be adjusted & + & + & + & \\
\hline Good Stability & + & + & + & \\
\hline Good appearance & - & - & $\mathrm{s}$ & \\
\hline Size & - & - & + & \\
\hline Durability & + & $\mathrm{s}$ & $s$ & \\
\hline Leg rest & + & $\mathrm{s}$ & + & \\
\hline Ease to use & - & + & + & \\
\hline Comfortably & + & + & + & \\
\hline$\Sigma+$ & 5 & 5 & 7 & \\
\hline$\Sigma-$ & 4 & 2 & 0 & \\
\hline$\Sigma \mathrm{s}$ & 1 & 3 & 3 & \\
\hline
\end{tabular}


Figure 3 below shows a manikin sit on a chair using the current computer table when using the computer. The manikin will be set by referring to the average anthropometric database. Figure 4 and 5 below indicate the complete RULA analysis with the left-hand side and right-hand side for current computer table. Figure 6 below shows the manikin sitting on the chair using an ergonomics table. Figure 7 and 8 below show the complete RULA analysis same as sitting posture using an ergonomic table.

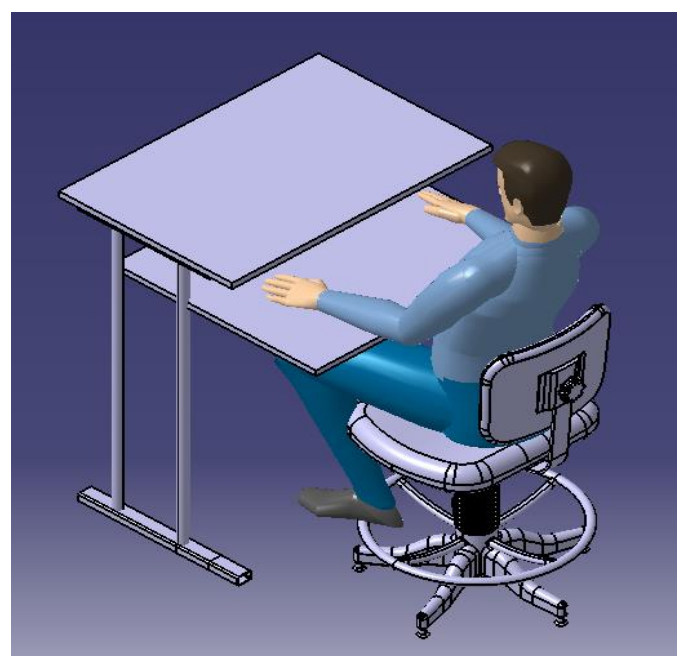

Figure 3: Sitting posture using the current computer table

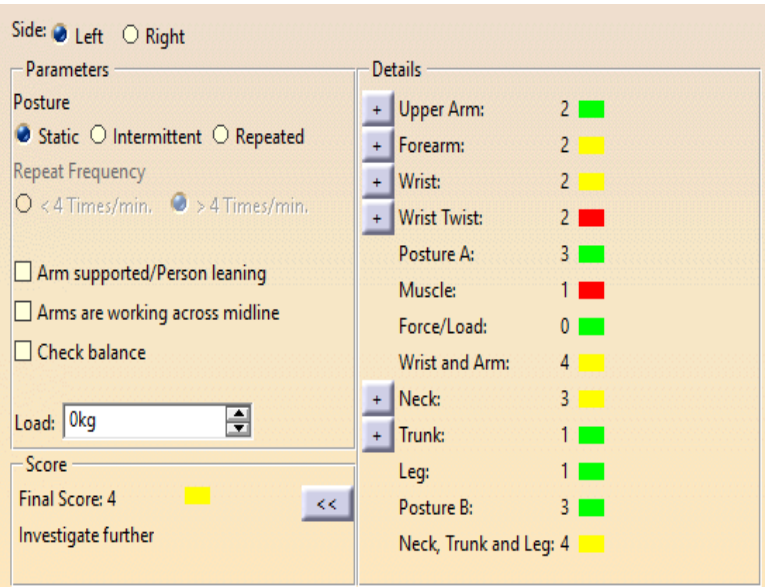

Figure 4: RULA analysis for left hand side

\begin{tabular}{|c|c|c|c|}
\hline \multicolumn{4}{|l|}{ Side: $O$ Left Right } \\
\hline \multirow{2}{*}{\multicolumn{2}{|c|}{$\begin{array}{l}\text { Posture } \\
\text { Static } O \text { Intermittent } O \text { Repeated }\end{array}$}} & + Upper Arm: & 3 \\
\hline & & + Forearm: & 2 \\
\hline \multirow{2}{*}{\multicolumn{2}{|c|}{$\begin{array}{l}\text { Repeat Frequency } \\
0<4 \text { Times } / \text { min. }\end{array}$}} & + Wrist: & 3 \\
\hline & & + Wrist Twist: & 20 \\
\hline \multirow{2}{*}{\multicolumn{2}{|c|}{$\square$ Arm supported/Person leaning }} & Posture A: & 4 \\
\hline & & Muscle: & $1 \square$ \\
\hline \multicolumn{2}{|l|}{$\square$ Arms are working across midline } & Force/Load: & $0 \square$ \\
\hline \multirow{2}{*}{\multicolumn{2}{|c|}{$\square$ Check balance }} & Wrist and Arm: & $5 \square$ \\
\hline & & + Neck: & 3 \\
\hline \multicolumn{2}{|l|}{ Load: $0 \mathrm{~kg}$} & + Trunk: & $1 \square$ \\
\hline \multirow{3}{*}{\multicolumn{2}{|c|}{$\begin{array}{l}\text { Score } \\
\text { Final Score: } 5 \\
\text { Investigate further and change soon }\end{array}$}} & Leg: & $1 \square$ \\
\hline & & Posture B: & $3=$ \\
\hline & & \multicolumn{2}{|c|}{ Neck, Trunk and Leg: 4} \\
\hline
\end{tabular}

Figure 5: RULA analysis for right hand side

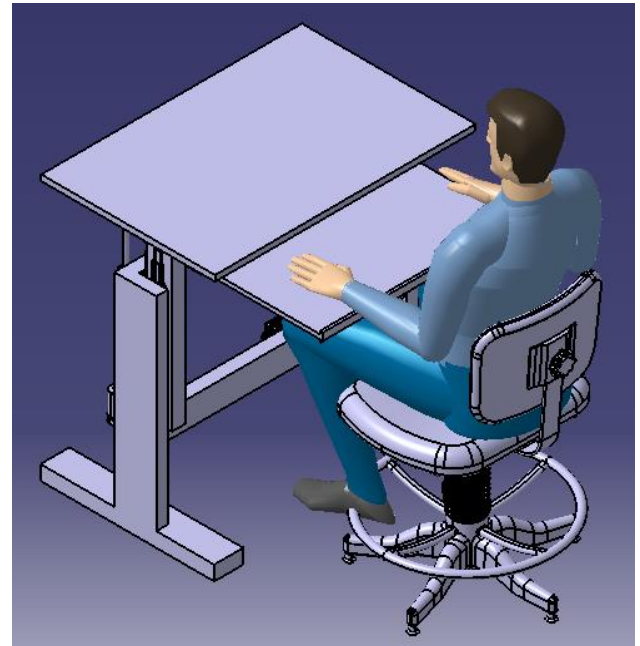

Figure 6: Sitting posture using the new ergonomics computer table

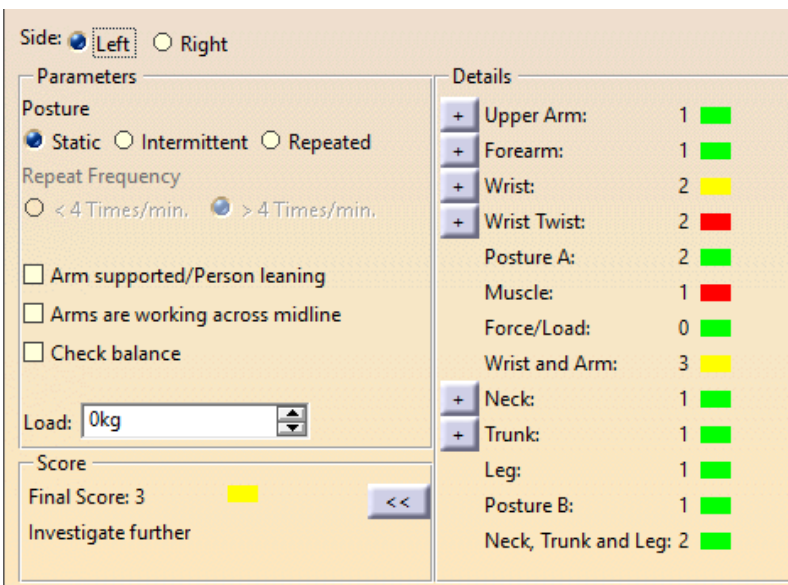

Figure 7: RULA analysis for left hand side

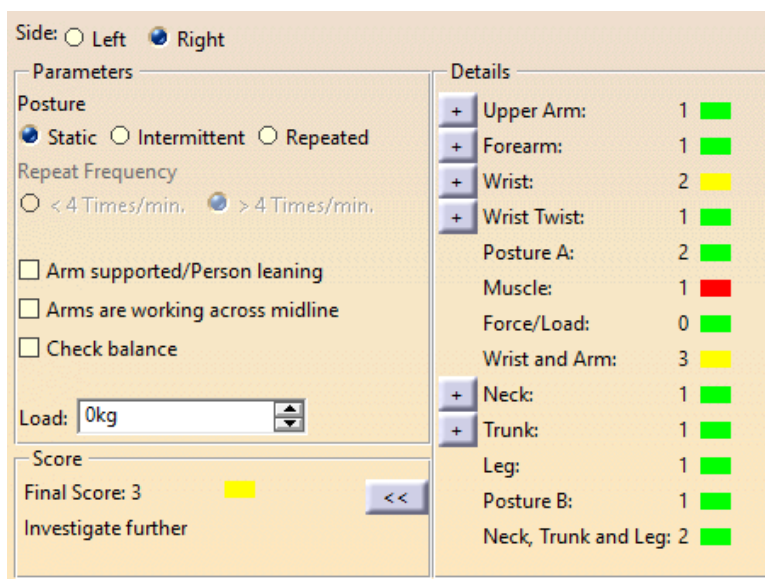

Figure 8: RULA analysis for the right-hand Side

\section{DISCUSSION}

The final results for both sides of the new design of the ergonomics computer table (sitting and standing) have been improved. Most of the posture problems of the body part have been solved, and only for the muscle part, it is recommended that further investigations are 
required to grasp a better comprehension and improvements can be made.

Figure 9 and 10 below show the improvements of a computer table can make, involving a test on respondent $A$, while Figure 11 and 12 below show the improvements of a computer table that was tested on respondent $\mathrm{B}$. The improvements can reduce the injuries or disorders of the users who work for a long time.

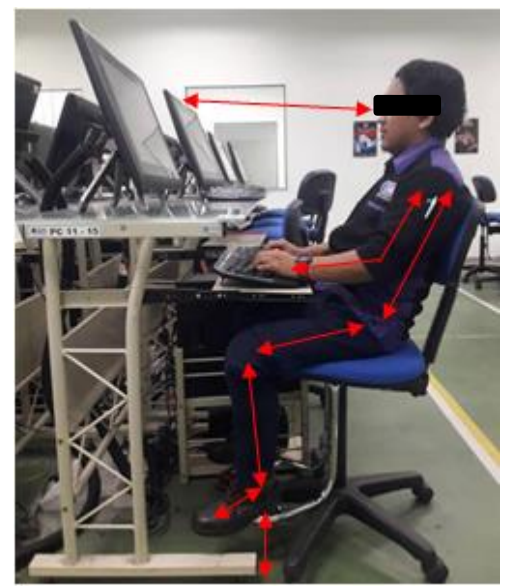

Figure 9: The sitting posture of Respondent $A$ with the current computer table

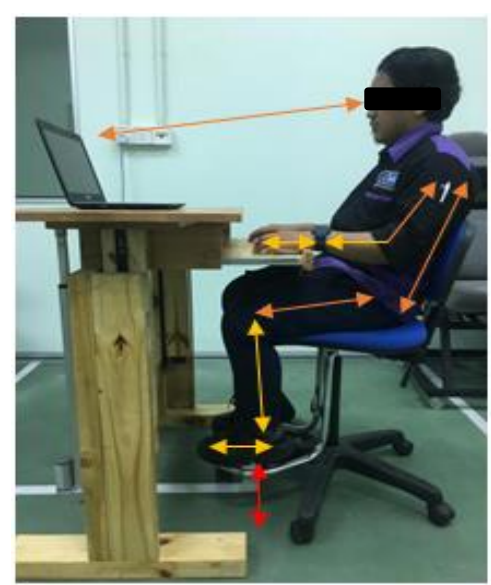

Figure 10: The sitting posture of Respondent $A$ using a new ergonomics computer table

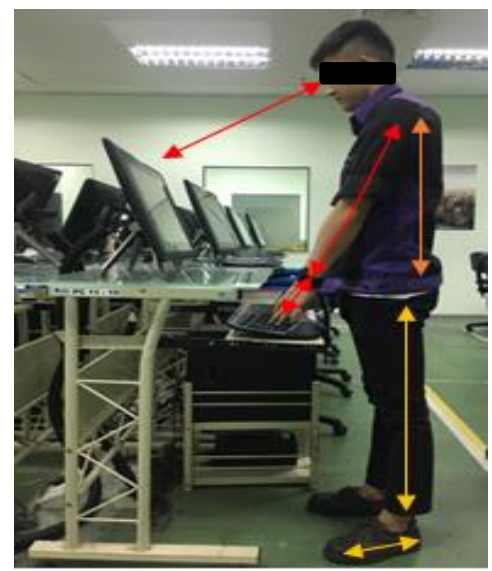

Figure 11: The standing posture of Respondent B using the current computer table

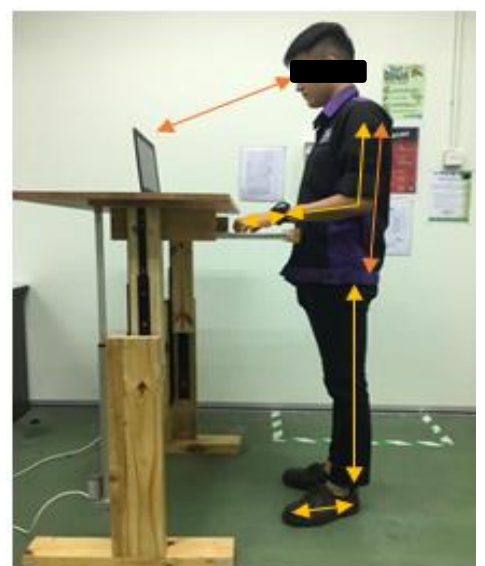

Fig. 12: The standing posture of Respondent $B$ using the new ergonomics computer table

\section{CONCLUSIONS}

A new ergonomics computer table is designed and developed, as shown in figure 13 below. This project is definitely related to the application of ergonomics aspects in designing the new ergonomics computer table to fit the student; resulting in having a good, working posture, but at the same time, eliminating the risks of injuries and disorders.

\begin{tabular}{|c|c|c|c|}
\hline TIEM & PART & DESCRIPTION & TIY. \\
\hline NO & NUMBER & TABLELEG & 2 \\
\hline 1 & 1 & ADJUSTALELEG & 2 \\
\hline 2 & 2 & LEG SUPPORT & 1 \\
\hline 3 & 3 & TABLE TOP SUPPORT & 1 \\
\hline 4 & 4 & TABLE TOP & 1 \\
\hline 5 & 5 & KEYBOARD TRAY HOLDER & 2 \\
\hline 6 & 6 & KEYBOARD TRAY & 1 \\
\hline 7 & 7 & HOUSING FOR DPDT SWITCH & 1 \\
\hline 8 & 8 & LINEAR ACTUATOR & 2 \\
\hline 9 & 9 & POWER SUPPLY & 1 \\
\hline 10 & 10 & DPDT SWITCH & 1 \\
\hline 11 & 11 & DRAWER SLIDE & 6 \\
\hline 12 & 12 & & \\
\hline
\end{tabular}
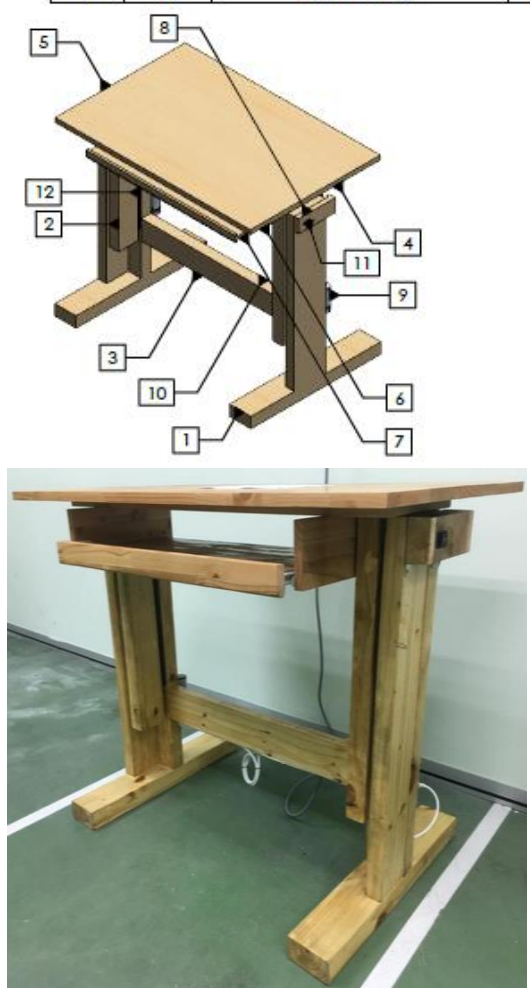

Figure 13: Shows the design of the new ergonomics table. 


\section{ACKNOWLEDGEMENTS}

We wish to express our gratitude to Universiti Teknikal Malaysia Melaka (UTeM) and special appreciation and gratitude to Centre of Research and Innovation Management (CRIM) and to Faculty of Engineering Technology Mechanical and Manufacturing to be specific Department of Manufacturing Technology from UTeM for giving the full cooperation, financial, and moral support in completing this research successfully. This project is under the following research grant scheme: PJP/2018/FTK(14D)/S01640.

\section{REFERENCES}

1. Scott Openshaw, Erin Taylor: Ergonomics and Design A Reference Guide: Allsteel Inc. Muscatine, lowa 52761-5257

2. Franssila, H., Okkonen, J. and Savolainen, R., 2016. Developing measures for information ergonomics in knowledge work. Ergonomics, 59(3), pp.435-448.

3. Tillman, B., Tillman, P., Rose, R.R. and Woodson, W.E: Human Factors and Ergonomics Design Handbook Third Edition. McGraw Hill Professional 2016.

4. Jan Dul, Bernard Weerdmeester: Ergonomics for Beginners: A Quick Reference Guide,CRC Press. Taylor \& Francis Group 2008.

5. RACT, A., 2013. Risk MacLeod, 1994 analysis and assessment methodologies in the work sites: On a review, classification and comparative study of the scientific literature of the period 2000-2009. Journal of Loss Prevention in the Process Industries, 24, pp.477-523.

6. Steven B. Heymsfield, Brianna Bourgeois, Bennett K. Ng, Markus J. Sommer, Xin Li \& John A. Shepherd: Digital anthropometry: a critical review: European Journal of Clinical Nutrition volume 72, pages680-687

7. O. Oduma, and S. I. Oluka: Comparative Analysis Of Anthropometric Dimensions Of Male And Female Agricultural Workers In South-Eastern Nigeria: Nigerian Journal of Technology (NIJOTECH) Vol. 36, No. 1, pp. $261-266$

8. E. N. Corlett: Background to sitting at work: research-based requirements for the design of work seats: Ergonomics Vol. 49, No. 14, 15 November 2006, 1538-1546

9. Jung, H.S., 2005. A product of an adjustable table and an adjustable chair for schools. International Journal of Industrial Ergonomics, 35(10), pp.955-969.
10. Hobson, D.A. and Molenbroek, J.F.M., 1990. Anthropometry and design for the disabled: Experiences with seating design for the cerebral palsy population. Applied ergonomics, 21(1), pp.43-54.

11. Hoque, A.S.M., Parvez, M.S., Halder, P.K. and Szecsi, T., 2014. Ergonomic design of classroom furniture for university students of Bangladesh. Journal of Industrial and Production Engineering, 31(5), pp.239-252.

12. Fredric Gerr, Michele Marcus, Cindy Ensor, David Kleinbaum et al. "A prospective study of computer users: I. Study design and incidence of musculoskeletal symptoms and disorders", American Journal of Industrial Medicine, 2002

13. Hoe, V.C., Urquhart, D.M., Kelsall, H.L. and Sim, M.R., 2018: Ergonomic interventions for preventing work-related musculoskeletal disorders of the upper limb and neck among office workers: US National Library of Medicine National Institutes of Health: CD008570.doi:10.1002/14651858.CD008570.p ub3.

14. Rahman, C.M., 2014. Study and analysis of work postures of workers working in a ceramic industry through rapid upper limb assessment (RULA). International Journal of Engineering, 5(03), p.8269.

15. Horn, D. and Salvendy, G., 2006. Consumerbased assessment of product creativity: A review and reappraisal. Human factors and ergonomics in manufacturing \& service industries, 16(2), pp.155-175. 